\title{
IV. Observations on loaded and unloaded barges, boats, beams, or floating bodies descending with streams or currents, and why the heavier end will go foremost
}

\section{George Orr Esq.}

To cite this article: George Orr Esq. (1810) IV. Observations on loaded and unloaded barges, boats, beams, or floating bodies descending with streams or currents, and why the heavier end will go foremost, Philosophical Magazine Series 1, 35:141, 31-35, DOI: 10.1080/14786441008563013

To link to this article: http://dx.doi.org/10.1080/14786441008563013

$$
\text { 曲 Published online: } 18 \text { May } 2009 .
$$

Submit your article to this journal 5

\section{凹 Article views: 2}


is also made with it, which, when applied upon copper or silver, furnishes a colour precisely similar to that of fine gold, and imitates this bright metal extremely well when applied in thin leaves to other metals: a colour which, I think, cannot be obtained in the same degree of perfection with any other metal.

I shall not dwell upon the different varieties of chromates of lead used in painting: they are already well known to artists, and are in great request on account of their beautiful colours, the facility with which they may be applied, and their great inalterability.

It is very probable that several other metallic chromates would also furnish beautiful colours if they were properly examined by painters.

IV. Observations on loaded and unloaded Barges, Boats, Beams, or flouting Bodies descending with Streams or Currents, and why the heavier End will go foremost. By George OrR, Esq.

$\mathbf{I}_{\mathbf{N}}$ addition to what I have already said on this subject, I now submit what follows to the consideration of scientific men : and as my object is an endeavour to attain the truth on so interesting a subject, I am ever ready to admit my errors where I am wrong, but hope that reason and good temper, free from peevishmess and personality, will ever regulate the dincussion of philosophical sulyjects.

When bocies of the description alluded to, or in fact any bodies that are specifically lighter than water, float in it, there are two powers always opposed to each other, that is, the specific gravities of the fluid and of the floating body; and in proportion as the differ more or less, in the same proportion will the two bodies oppnse each other : for the less specifically heavy any floating body is, the less power will it possess to contend against the fluid in its endeavours to sink or descend; and of course it will follow that it will float nearer the surface. When water is perfectly at rest, it has found its level, and its surface presents a borizontal plane; or in other words, all its particles press or gravitate towards the centre of the earth in perpendicular and right lines; but on any change from this state of rest taking place, the particles of water are, by the force of gravitation, put in motion, and will endeavour to find their level again, or continue to move on an inclined plane; and all bodies suspended in the fluid, or floating on the surface more or less deep, being subject 
to the same laws of gravitation, take their direction with the moving fluid, and thus pass down the same inclined plane, with a motion more or less accelerated as such bodies are heavier or lighter; that is, as they possess a greater or less power to overcome the resistance that may be opposed to them.

I think it is manifest from what is here said, that the motion which takes place with regard to both fluid and solid, is owing to the attraction of gravitation; and as the velocities of bodies arising from this power are greatest in descending the perpendicular to the plane. of the horizon, so it will follow that these velocities will be diminished until the line, along which they may descend, being carried from the perpendicular round the whole quadrant or right angle, arrives at the level or parallel to the horizon, where, if the power of descending be totally opposed, or the centre of gravity altogether supported, no motion will take place. Hence if will follow that the velocity of a stream, river, or current, and of course of bodies that float in them, will be greater or less, as the inclination of the plane on which they descend departs more or less from the line bounding the horizontal plane.

Loaded barges, beams of heavy wood, \&c., without towing, and that float with the tide, will make a quicker progress than the tide; the same will take place in a river or stream where there is no tide. Captain Burney having asked the bargemen on the Thames the reason of this, their reply was, "That loaded barges had more hold of the tide from their floating deeper than unloaded ones." This was but a bad way of accounting for it; but some reason must be assigned by those who continually observed this, and who were iguorant of the real cause of it.

The reason of this quicker progress scems to me to be this : any solid floating in a fluid, and descending with it, acts altogetber in one mass; and its particles thus acting together conspire to overcome the resistance they meet, and to divide the fluid, which, easily yielding to any pressure, will make way for the body in its descent pressing forward. Besides, the particles of the fluid do not act in conjunction, and being easily separated they will roll about and impede each other by their friction, not only against each other, but also against the sides of the river, and the bed on which they descend. To this may be added, that less friction takes place between the fluid and solid, as they attract each other less, than between the innumerable particles of the fluid; consequently the solid will glide on, or slip through the liquid 
liquid body with a greater degree of velocity than the fluid, under the circumstances already enumerated, can attain.

Captain B. says, this greater progressive motion in the floating body is not owing to a more rapid under-current. I think not, but to the causes already assigned. Captain B. says, the surface of the ocean is an inclined plane. I have stated in some letters several months ago in the Philosophical Magazine, that the surface of the ocean, owing to the attraction of gravitation and its laws, and to the impression of the winds, \&c., cunsists of an infinity of inclined planes, or ascents and descents.

No collision could take place between a heavier and lighter barge or body passing London bridge with the sebb of the tide, let them be ever so near, provided the heavier hody were foremost, because on its descent it will, from its greater weight, acquire a momentum which will carry it on more rapidly than the lighter body; but if the lighter body were foremost and very near, it might be overtaken, and a collision take place.

When the wind blows strong into any bay, or against an embayed coast, there must be an under-current, because the wind prevents the return of the accumulated water along the surface. All pressure on bodies floating with streams must, whether the pressure be perpendicular or oblique, increase their progress :- if the pressure be perpendicular, it adds to the weight, and consequently to their power of overcoming resistance on the part of the fluid: if the pressure be oblique, and in direction of the motion, it will, besides increasing the weight, give impulse.

The reason why ships at sea that are deeply loaded make less progress on a voyage than those that are lighter, and which seems to be in contradiction to what was last stated, seems to me to arise from the following cause: that is, that what they gain by their gravity over a lighter vessel in descending from the top of the wave or inclinel plane, they lose in ascending the next; for it is manifest that the surface of the ocean consists of innumerable inclined planes, or ascents and descents; but in a river or running stream the whole progress is on a descent.

Two pieces of wood of the same kind and of the same weight, but of different shapes, the one, for instance, a cylinder with all its transverse diameters equal, the other of a conical form, with its transverse diameters or lines all unequal, would, in my opinion, differ considerably in their progress in the same fluid, the cone making greater way than the cylinder; and to this I presume it may be principally atVol, 35. No. 141. Jan. 1810. C tributed 
tributed why one ship sails better than another, and which, on some future occasion, I may attempt to demonstrate.

Timber used at sea to find the direction of any current ought to be in its shape conical, and a good deal so, but the base of the cone to be rounded, or the sharp angles taken off, in order that it may pass more fairly through the water; for wood of this shape wiil take the direction better, and be more easily observed: in such cases there should always be two eonical timbers, and if they both take the same direction, the tendency of the current is certainly proved. No experiments can be made on this subject with South Sea clubs, such as captain B. used, nor with anything that will sink in water, that is, with any body specifically heavier than water.

Supposing a barge loaded at one end and empty at the other, and without a helm, if it floated in a fair and regular stream without currents; it would certainly proceed with the heavy end foremost, for the same reasons that a conical piece of wood, or even a cylindrical one loaded at one end, would go with their heavy end foremost in a fluid, though originally placed in a contrary direction: it would be the same with the cone and cylinder, if placed across a dry inclined plane; that end containing the greatest quantity of matter, from its power of overcoming resistance, would always have a tendency to be foremost. The inclined plane of rivers and streams must, from the number of inequalities at bottom, be a very irregular one-the current will partake of those irregularities, and the motion of bodies that float in them must be affected by them in a certain degree.

Lastly, Does a body floating down a stream or current, and which has a quicker progress than the stream or current, receive any aldition to its motion from the motion of the fluid? I think it does not; that it is only indebted to the fluid for its suspension, but that it is to its own gravity, and acting in one mass, that it is indebted for its greater progress. On the contrary, I think it loses in its velocity or progressive motion; for though the floating body be specifically lighter than the water, and of course one would imagine that it would move slower, still, owing to the causes already enumerated, its progress is quicker : but there is a drawback on this progress; because, if the solid overtake the water, part of its force must be wasted against that body which moves slower, but in the same direcion. This case is analogous to that of two balls moving 
in the same direction with different velocities; that with the greater velocity, on overtaking the other, communicates part of its force, and of course loses so much in its velocity.

\section{On Neri Materni.}

\section{To Mr. Tilloch.}

Sir, $T_{\text {he last Number of your Philosophical Magazine }}$ contains a discussion, by one of your ingenious correspondents, in support of the old prejudice that certain congenital marks or excrescences, commonly called ncevi maierni, originate from the influeuce of the mind of the parent. As the paper, no doubt, was written with a serious object, I comply with the writer's request in forwarding to you for publication some observations on the subject.

It is agreed that nevi materni resemble known objects in nothing more than form; although, as ENCEPS (the writer's signature) observes, "more than one volume has been filled with reputed instances of the effects of the mother's imagination upon her offepring." The forms, how'ever, of ncevi materni in general are so far from having a resemblance to any known object, that the experience of practitioners, who are in the daily habits of operating on some, and seeing many others, proves as much as extensive experience can prove, that the relations of navi materni resembling a bunch of grapes, or a bit of bacon, are to be classed with the idle tales of the nursery. Even Enceps himself "was for a long time prepossessed with the same notion," viz. that such fanciful forms of ncevi materni were " idle tales," till a case "was related to him by an intelligent friend who had seen a child born with only one leg, as well as its mother, who declared her firm belief that the cause of this imperfection in her child was a violent fright which she experienced from seeing a beggar suddenly uncover the wounded stump of his thigh." This, however, is not an example of naevus maternus, but of monstrosity. Now I will seriously ask Enceps, at what period of pregnancy this uniortunate mother received such a violent fright. In the latter months of prognancy, after the limbs of the foetus had been formed? The separation of a limb, and its still more extraordiuary annihilativ:1, must.then be explained as the effects of imagination, - or in the early months of pregnancy, before the ovum liad become organ- 